\title{
Peningkatan Komponen Hasil dan Mutu Benih Dua Varietas Okra melalui Penjarangan Buah
}

\section{Excalation of Yield Component and Seed Quality on Two Varieties of Okra through Fruit Thinning}

\author{
Prajna Jaya Perwira ${ }^{1}$, Tatiek Kartika Suharsi ${ }^{2 *}$, dan Muhamad Syukur ${ }^{2}$
}

\author{
${ }^{1}$ Program Studi Agronomi dan Hortikultura, Sekolah Sarjana, Institut Pertanian Bogor \\ ${ }^{2}$ Departemen Agronomi dan Hortikultura, Fakultas Pertanian, Institut Pertanian Bogor \\ (Bogor Agricultural University), Jl. Meranti, Kampus IPB Darmaga, Bogor 16680, Indonesia
}

Diterima 20 Agustus 2019/Disetujui 3 Desember 2019

\begin{abstract}
The fruit thinning treatment is known to be able to improve seed quality. This research aimed to increase the yield component and seed quality on two okra varieties (Naila and Zahira) through fruit thinning. This experiment was conducted in May until September 2018 at the Leuwikopo IPB Field, Postharvest Laboratory, and Seed Testing Laboratory, Department of Agronomy and Horticulture, Faculty of Agriculture, Bogor Agricultural University. This experiment conducted using the two-factors nested design, which is a fruit thinning factor as subplots consisting of five levels and okra varieties consisting of two levels. The results showed that the fruit thinning factor influenced the parameters of yield components (fruit length and weight per fruit) and 1,000 seeds weight. The variety factor influenced most of the yield component parameters and seed quality in okra plants. The thinning treatment of the first two fruits and elimination of one fruit interval resulted in the highest physical quality of seed based on 1,000 seeds weight (67.99 g).
\end{abstract}

Keywords: 1,000 seed weight, physical quality

\section{ABSTRAK}

Perlakuan penjarangan buah diketahui mampu meningkatkan mutu benih. Penelitian ini bertujuan untuk meningkatkan komponen hasil panen dan mutu benih pada dua varietas okra (Naila dan Zahira) melalui penjarangan buah. Percobaan ini dilakukan pada Mei-September 2018 di Kebun Percobaan IPB Leuwikopo, Laboratorium Pascapanen dan Laboratorium Pengujian dan Penyimpanan Benih, Departemen Agronomi dan Hortikultura, Fakultas Pertanian, Institut Pertanian Bogor. Percobaan ini dilakukan dengan menggunakan rancangan tersarang dua faktor, dimana penjarangan buah sebagai anak petak terdiri atas lima taraf dan varietas okra terdiri atas dua taraf. Hasil penelitian menunjukkan faktor penjarangan buah mempengaruhi parameter komponen hasil (panjang buah dan bobot per buah) dan bobot 1,000 butir. Faktor varietas mempengaruhi sebagian besar parameter komponen hasil dan mutu benih pada tanaman okra. Perlakuan penjarangan dua buah pertama dan dieliminasi selang satu buah menghasilkan mutu fisik benih tertinggi berdasarkan parameter bobot 1,000 butir (67.99 g).

Kata kunci: bobot 1,000 butir, mutu fisik

\section{PENDAHULUAN}

Okra merupakan tanaman sayur yang berasal dari benua Afrika yaitu negara Ethiopia. Okra (Abelmoschus esculentus (L.) Moench) mulai dikenal sebagai tanaman sayur pada abad ke-12. Buah okra menjadi salah satu obat alternatif dan terbukti dapat dimanfaatkan sebagai obat herbal diabetes mellitus dan hipertensi (Dubey dan Mishra, 2017). Tanaman okra di Indonesia merupakan tanaman introduksi dan belum

\footnotetext{
* Penulis untuk korespondensi. e-mail: tatiek.kartika55@gmail. com
}

dikenal secara luas namun memiliki banyak manfaat untuk konsumsi sayuran dan kesehatan. Okra cocok ditanam di berbagai jenis tanah sehingga berpotensi besar untuk dikembangkan di Indonesia (Litbangtan, 2017).

Optimasi mutu benih perlu dilakukan untuk menghasilkan pertumbuhan dan produksi tanaman yang baik dan optimum. Pengujian viabilitas benih dan uji vigor benih dapat menunjukkan mutu fisiologi benih (Bortey dan Dzomeku, 2016). Menurut Darmawan et al. (2014), benih yang bermutu tinggi akan menghasilkan tanaman yang memiliki pertumbuhan normal. Tanaman yang memiliki pertumbuhan normal mampu mengoptimalkan hara dan fotosintat yang diterima tanaman sehingga produktivitas 
akan optimal. Peningkatan mutu benih salah satunya dapat dilakukan dengan penjarangan buah pada beberapa tanaman.

Penjarangan buah dilakukan dengan melakukan pengurangan jumlah buah untuk memaksimalkan translokasi fotosintat pada buah yang dipertahankan. Tujuan dari penjarangan buah adalah buah yang dipertahankan berkembang optimal dan mutu benih yang dihasilkan lebih baik. Jumlah buah pada suatu tanaman akan berpengaruh terhadap kualitas buah (Sakhidin, 2010). Kualitas buah tersebut akan mempengaruhi mutu benih yang dihasilkan seperti ukuran benih serta jumlah benih khususnya pada tanaman okra. Besaran fotosintat yang diterima buah pada tanaman tomat mempengaruhi ukuran buah dan bobot 1,000 butir benih (Tabasi et al., 2011) serta meningkatkan vigor benih yang akan menghasilkan tanaman yang sehat dan perakaran kuat (Pathrirana et al., 2014). Penelitian ini bertujuan untuk meningkatkan komponen hasil panen dan mutu benih pada kedua varietas okra melalui penjarangan buah.

\section{BAHAN DAN METODE}

Penelitian ini terdiri atas dua faktor yaitu penjarangan buah dan varietas okra. Faktor penjarangan buah terdiri atas lima taraf yaitu tanpa penjarangan buah (kontrol), penjarangan buah dengan satu buah pertama dibuang dengan penjarangan selang satu buah (1.1 P), penjarangan buah dengan satu buah pertama dibuang dengan penjarangan selang dua buah (1.2 P), penjarangan buah dengan dua buah pertama dibuang dengan penjarangan selang satu buah (2.1 P), dan penjarangan buah dengan dua buah pertama dibuang dengan penjarangan selang dua buah (2.2 P) (Gambar 1). Faktor varietas okra terdiri atas dua taraf yaitu varietas Zahira (okra merah) dan Naila (okra hijau).

Percobaan ini dilakukan pada Mei sampai dengan September 2018. Penanaman okra dilakukan menggunakan rancangan tersarang (nested design) di Kebun Percobaan
IPB Leuwikopo, Departemen Agronomi dan Hortikultura, Fakultas Pertanian, Institut Pertanian Bogor. Perlakuan penjarangan buah (anak petak) sebanyak 3 ulangan tersarang dalam perlakuan varietas okra (petak utama) sehingga terdapat total 30 satuan percobaan. Setiap satuan percobaan memiliki luasan $7 \mathrm{~m}$ x $1 \mathrm{~m}$ dengan jarak antar petak sebesar $60 \mathrm{~cm}$. Jarak tanam yang digunakan yaitu $70 \mathrm{~cm} \mathrm{x} 70 \mathrm{~cm}$ sehingga terdapat 20 tanaman per petak dengan 10 tanaman digunakan sebagai tanaman contoh. Selama penanaman dilakukan kegiatan pemeliharaan yaitu pemasangan ajir, pemupukan dan pengendalian OPT.

Pengamatan percobaan dilakukan terhadap parameter komponen hasil tanaman, mutu fisik dan mutu fisiologi benih di Laboratorium Pascapanen dan Laboratorium Pengujian dan Penyimpanan Benih, Departemen Agronomi dan Hortikultura, Fakultas Pertanian, Institut Pertanian Bogor. Pengamatan komponen hasil terdiri atas peubah jumlah buah per tanaman dengan hitungan manual, dan mengambil tiga contoh buah secara acak per tanaman contoh untuk diukur parameter bobot (bobot buah per tanaman, bobot benih per tanaman, bobot buah per buah, bobot benih per buah, dan bobot benih per butir) dengan menggunakan timbangan digital, panjang buah dengan menggunakan pita ukur, diameter buah dengan menggunakan jangka sorong, dan jumlah benih per buah dihitung secara manual. Pengamatan mutu fisik terdiri dari bobot 1,000 butir Bobot Kering Benih dan Kadar Air benih, sedangkan pengamatan mutu fisiologi benih terdiri dari daya berkecambah, indeks vigor, kecepatan tumbuh, dan bobot kering kecambah normal, kedua pengamatan mutu benih berdasarkan ISTA (2014). Germinator IPB 72-1 digunakan pada sebagian pengujian mutu fisiologi benih.

Data hasil pengamatan dianalisis secara statistik dengan anova pada taraf $\alpha=5 \%$ (selang kepercayaan 95\%). Jika anova menunjukan perlakuan berpengaruh nyata maka dilanjutkan dengan uji lanjut DMRT pada taraf $\alpha=$ 5\%. Pengujian dilakukan dengan software SAS 9.1 dan Microsoft Excel.

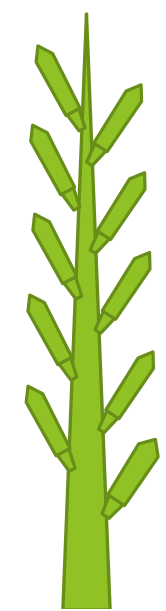

Kontrol

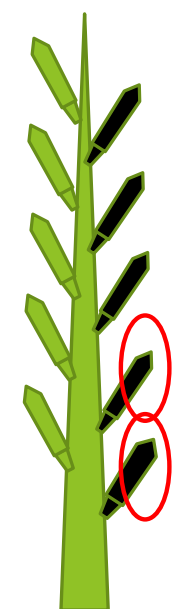

$1,1 \mathrm{P}$

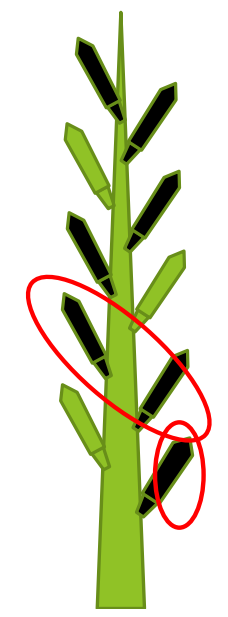

$1,2 \mathrm{P}$

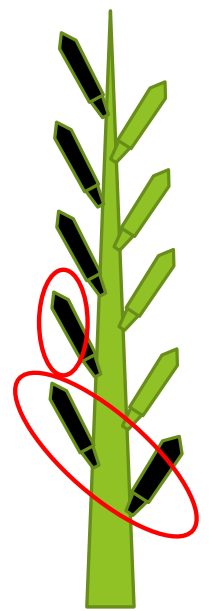

2.1 P

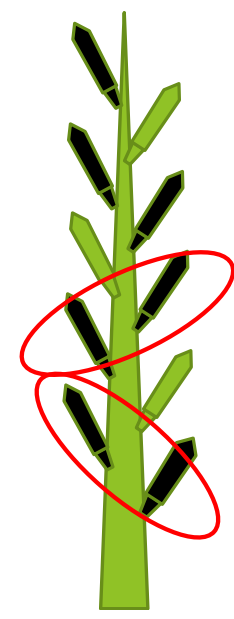

$2,2 \mathrm{P}$

Gambar 1. Ilustrasi taraf penjarangan buah okra (Keterangan: buah berwarna hitam menunjukkan buah yang dijarangkan) 


\section{HASIL DAN PEMBAHASAN}

Pengaruh Penjarangan Buah dan Varietas terhadap Komponen Hasil Tanaman Okra

Penjarangan buah menurunkan jumlah buah per tanaman, bobot buah per tanaman dan bobot benih per tanaman, sedangkan varietas menghasilkan pengaruh yang berbeda nyata terhadap jumlah buah per tanaman, bobot buah per tanaman dan bobot benih per tanaman. Perlakuan kontrol menghasilkan rata-rata jumlah buah per tanaman (19.05 buah), bobot buah per tanaman (255.96 g), dan bobot benih per tanaman (112.45 g) nyata paling besar. Pengaruh penjarangan buah antar perlakuan menunjukkan hasil yang tidak berbeda nyata pada ketiga karakter (Tabel 1). Buah yang dipertahankan dari hasil penjarangan buah meningkatkan bobot buah strawberi berdasarkan penelitian Menzel (2019). Hasil penelitian ini menunjukkan hal menarik bahwa peningkatan bobot per buah hasil perlakuan penjarangan dua buah pertama dengan selang eliminasi satu buah (15.77 g) pada Tabel 2 belum bisa mengimbangi penurunan bobot buah per tanaman pada perlakuan penjarangan dua buah pertama dengan selang eliminasi satu buah dibanding dengan perlakuan kontrol pada Tabel 1. Penurunan bobot buah per tanaman dan bobot benih per tanaman mengikuti dari penurunan jumlah buah per tanaman pada tanaman okra sehingga perlakuan kontrol terlihat memiliki hasil panen yang lebih besar dibandignkan hasil perlakuan penjarangan buah. Berdasakan faktor varietas, Naila menghasilkan jumlah buah per tanaman (13.08 buah), bobot buah per tanaman (204.34 g) dan bobot benih per tanaman $(84.01 \mathrm{~g})$ yang lebih besar dibandingkan varietas Zahira (Tabel 1).

Penjarangan buah meningkatkan nilai panjang buah okra dan bobot per buah namun tidak berpengaruh terhadap diameter buah okra. Panjang buah okra paling besar dihasilkan pada penjarangan dua buah pertama dengan selang eliminasi dua buah $(20.00 \mathrm{~cm})$ dan bobot per buah paling besar dihasilkan pada penjarangan dua buah pertama dengan selang eliminasi satu buah (15.77 g). Hal tersebut menunjukkan penjarangan buah berpengaruh nyata terhadap peningkatan ukuran khususnya panjang buah dan bobot buah. Hal serupa ditunjukkan pada penelitian Erogul dan Sen (2015), bahwa penjarangan buah dengan menggunakan

Tabel 1. Pengaruh interaksi antara penjarangan buah dengan varietas terhadap jumlah buah per tanaman, bobot buah per tanaman pada tanaman okra, dan bobot benih per tanaman

\begin{tabular}{lccccccccc}
\hline \multirow{2}{*}{$\begin{array}{l}\text { Penjarangan } \\
\text { buah }\end{array}$} & \multicolumn{3}{c}{ Jumlah buah per tanaman } & \multicolumn{3}{c}{ Bobot buah per tanaman $(\mathrm{g})$} & \multicolumn{3}{c}{ Bobot benih per tanaman $(\mathrm{g})$} \\
\cline { 2 - 10 } & Naila & Zahira & Rata-rata & Naila & Zahira & Rata-rata & Naila & Zahira & Rata-rata \\
\hline Kontrol & $21.26 \mathrm{a}$ & $16.83 \mathrm{a}$ & $19.05 \mathrm{a}$ & $297.84 \mathrm{a}$ & $214.10 \mathrm{a}$ & $255.96 \mathrm{a}$ & $128.37 \mathrm{a}$ & $96.65 \mathrm{a}$ & $112.45 \mathrm{a}$ \\
$1.1 \mathrm{P}$ & $11.33 \mathrm{~b}$ & $10.67 \mathrm{~b}$ & $11.00 \mathrm{~b}$ & $185.98 \mathrm{~b}$ & $143.19 \mathrm{~b}$ & $164.58 \mathrm{~b}$ & $74.37 \mathrm{~b}$ & $64.57 \mathrm{~b}$ & $69.47 \mathrm{~b}$ \\
$1.2 \mathrm{P}$ & $11.13 \mathrm{~b}$ & $9.93 \mathrm{~b}$ & $10.53 \mathrm{~b}$ & $175.90 \mathrm{~b}$ & $145.93 \mathrm{~b}$ & $160.91 \mathrm{~b}$ & $73.06 \mathrm{~b}$ & $61.15 \mathrm{~b}$ & $67.10 \mathrm{~b}$ \\
$2.1 \mathrm{P}$ & $11.33 \mathrm{~b}$ & $11.30 \mathrm{~b}$ & $11.31 \mathrm{~b}$ & $189.52 \mathrm{~b}$ & $167.44 \mathrm{~b}$ & $178.48 \mathrm{~b}$ & $76.65 \mathrm{~b}$ & $72.72 \mathrm{~b}$ & $74.69 \mathrm{~b}$ \\
$2.2 \mathrm{P}$ & $10.36 \mathrm{~b}$ & $11.26 \mathrm{~b}$ & $10.81 \mathrm{~b}$ & $172.47 \mathrm{~b}$ & $162.98 \mathrm{~b}$ & $167.72 \mathrm{~b}$ & $67.60 \mathrm{~b}$ & $73.18 \mathrm{~b}$ & $70.39 \mathrm{~b}$ \\
\hline Rata-rata & $13.08 \mathrm{~A}$ & $12.00 \mathrm{~B}$ & & $204.34 \mathrm{~A}$ & $166.72 \mathrm{~B}$ & & $84.01 \mathrm{~A}$ & $73.63 \mathrm{~B}$ & \\
\hline
\end{tabular}

Keterangan: Angka yang diikuti huruf yang sama pada kolom yang sama dan angka yang diikuti huruf kapital yang sama pada baris dan peubah yang sama menunjukkan hasil yang tidak berbeda nyata pada uji DMRT dengan taraf $\alpha=0.05$. P = Penjarangan buah; $\mathrm{V}=$ Varietas

Tabel 2. Pengaruh penjarangan buah dan varietas terhadap panjang buah, diameter buah, dan bobot per buah pada tanaman okra

\begin{tabular}{lccc}
\hline Perlakuan & Panjang buah $(\mathrm{cm})$ & Diameter buah $(\mathrm{cm})$ & Bobot per buah $(\mathrm{g})$ \\
\hline Penjarangan buah & & \\
Kontrol & $18.84 \mathrm{~b}$ & 2.24 & $13.39 \mathrm{~b}$ \\
$1.1 \mathrm{P}$ & $19.85 \mathrm{a}$ & 2.45 & $14.92 \mathrm{a}$ \\
$1.2 \mathrm{P}$ & $19.41 \mathrm{ab}$ & 2.61 & $15.28 \mathrm{a}$ \\
$2.1 \mathrm{P}$ & $19.97 \mathrm{a}$ & 2.29 & $15.77 \mathrm{a}$ \\
$2.2 \mathrm{P}$ & $20.00 \mathrm{a}$ & 2.29 & $15.58 \mathrm{a}$ \\
Varietas & & & \\
Naila & $21.25 \mathrm{a}$ & 2.47 & $15.91 \mathrm{a}$ \\
Zahira & $17.97 \mathrm{~b}$ & 2.28 & $14.07 \mathrm{~b}$ \\
\hline
\end{tabular}

Keterangan: Angka yang diikuti huruf yang sama dalam kolom yang sama menunjukkan hasil yang tidak berbeda nyata pada uji DMRT dengan taraf $\alpha=0.05$ 
$\mathrm{GA}_{3}$ berpengaruh terhadap peningkatan ukuran buah plum Jepang. Tabasi et al. (2011) juga menuturkan, perlakuan penjarangan buah dengan menjarangkan lima buah per tanaman tomat mampu meningkatkan bobot buah tomat. Varietas Naila menghasilkan panjang buah $(21.25 \mathrm{~cm})$ dan bobot per buah (15.91 g) yang lebih besar dibandingkan varietas Zahira (Tabel 2).

Menurut Delgado et al. (2010), penjarangan buah berpengaruh meningkatkan jumlah benih, rata-rata bobot benih, dan total bobot benih pada tanaman Cistus ladanifer (L.). Hal berbeda ditunjukkan pada parameter bobot benih per buah, jumlah benih per buah, dan bobot benih per butir pada tanaman okra yang tidak dipengaruhi oleh penjarangan buah. Varietas menghasilkan bobot benih per butir yang berbeda nyata dan dua karakter lainnya tidak berbeda nyata. Varietas Naila $(0.067 \mathrm{~g})$ memiliki bobot benih per butir yang lebih besar dibandingkan Zahira (Tabel 3).

\section{Pengaruh Penjarangan Buah dan Varietas terhadap Mutu Benih Tanaman Okra}

Menurut Borras et al. (2004), hasil perlakuan pengurangan jumlah polong pada tanaman kedelai dan bulir pada gandum didapatkan nilai Kadar Air benih di bawah 20\% setelah dilakukan pengeringan. Terdapat perbedaan hasil interaksi antara varietas Naila dan Zahira terhadap nilai kadar air setelah dilakukan pengeringan. Penjarangan buah tidak mempengaruhi kadar air benih Naila namun berpengaruh terhadap kadar air Zahira. Hal tersebut ditunjukkan pada nilai kadar air benih varietas Naila pada perlakuan kontrol $(12.70 \%)$ yang tidak berbeda nyata antar perlakuan penjarangan buah, sedangkan pada varietas Zahira pada perlakuan kontrol (13.43\%) memliki nilai kadar air terendah dibandingkan dengan penjarangan buah lainnya namun tidak berbeda nyata dibandingkan dengan nilai kadar air benih pada perlakuan penjarangan satu buah pertama dengan selang satu buah (13.63\%) dan perlakuan penjarangan dua buah pertama dengan selang satu buah (14.03\%). Varietas Naila memiliki nilai rata-rata kadar air benih (12.50\%) yang lebih rendah dibandingkan dengan benih Zahira (14.37\%) (Tabel 4). Hal tersebut menunjukkan kadar air pada benih okra sudah dibawah 20\% namun nilainya berfluktuatif dan tidak dapat ditekan kembali angka penurunan kadar air benih secara berkelanjutan melalui perlakuan penjarangan buah. Yuniarti et al. (2013) menambahkan bahwa benih dengan kadar air yang tinggi menjadi salah satu faktor

Tabel 3. Pengaruh penjarangan buah dan varietas terhadap bobot benih per buah, jumlah benih per buah dan bobot benih per butir pada tanaman okra

\begin{tabular}{lccc}
\hline Perlakuan & Bobot benih per buah $(\mathrm{g})$ & Jumlah benih per buah & Bobot benih per butir $(\mathrm{g})$ \\
\hline Penjarangan buah & & & \\
Kontrol & 5.88 & 92.61 & 0.061 \\
$1.1 \mathrm{P}$ & 6.29 & 93.28 & 0.066 \\
$1.2 \mathrm{P}$ & 6.36 & 95.93 & 0.066 \\
$2.1 \mathrm{P}$ & 6.59 & 97.50 & 0.066 \\
$2.2 \mathrm{P}$ & 6.50 & 101.10 & 0.065 \\
Varietas & & & \\
Naila & 6.48 & 96.65 & $0.067 \mathrm{a}$ \\
Zahira & 6.17 & 95.52 & $0.063 \mathrm{~b}$ \\
\hline
\end{tabular}

Keterangan: Angka yang diikuti huruf yang sama dalam kolom yang sama menunjukkan hasil yang tidak berbeda nyata pada uji DMRT dengan taraf $\alpha=0.05$

Tabel 4. Pengaruh interaksi antara penjarangan buah dengan varietas terhadap kadar air benih okra

\begin{tabular}{llcc}
\hline \multirow{2}{*}{ Penjarangan buah } & & Kadar air benih (\%) & Rata-rata \\
\cline { 2 - 4 } & Naila & Zahira & 13.07 \\
\hline Kontrol & 12.70 & $13.43 \mathrm{c}$ & 13.16 \\
$1.1 \mathrm{P}$ & 12.69 & $13.63 \mathrm{c}$ & 14.08 \\
$1.2 \mathrm{P}$ & 12.46 & $15.71 \mathrm{a}$ & 13.52 \\
$2.1 \mathrm{P}$ & 13.01 & $14.03 \mathrm{bc}$ & 13.36 \\
$2.2 \mathrm{P}$ & 11.66 & $15.07 \mathrm{ab}$ & \\
\hline Rata-rata & $12.50 \mathrm{~B}$ & $14.37 \mathrm{~A}$ & \\
\hline
\end{tabular}

Keterangan: Angka yang diikuti huruf yang sama pada kolom yang sama dan angka yang diikuti huruf kapital yang sama pada baris yang sama menunjukkan hasil yang tidak berbeda nyata pada uji DMRT dengan taraf $\alpha=0.05$ 
kemunduran benih karena meningkatnya respirasi sehingga benih menjadi rentan terkena cendawan. Benih okra dipanen dari buah yang telah masak fisiologi yang ditandai dengan buah yang mengering dan kecoklatan (Litbangtan, 2017). Benih yang telah dikering anginkan akan memiliki kadar air yang rendah sehingga aman untuk disimpan.

Pengaruh penjarangan buah menunjukkan hanya bobot 1,000 butir benih okra yang dipengaruhi oleh penjarangan buah dari enam parameter mutu benih. Penjarangan dua buah pertama dengan selang satu buah menghasilkan bobot 1,000 butir benih terbesar (67.99 g) yang tidak berbeda nyata dengan perlakuan penjarangan satu buah pertama dengan selang satu buah (67.89 g) dan perlakuan penjarangan satu buah pertama dengan selang dua buah (66.39 g) (Tabel 5). Hal ini didukung oleh penelitian Pathirana et al. (2014), bahwa penjarangan buah $5.2 \mathrm{P}$ dan $5.5 \mathrm{P}$ meningkatkan bobot 1,000 butir benih tomat.
Perlakuan kontrol menghasilkan viabilitas benih dan vigor benih yang tidak berbeda nyata dibandingkan dengan perlakuan penjarangan buah pada tanaman okra. Viabilitas benih kontrol ditunjukkan oleh parameter daya berkecambah $(86.00 \%)$, bobot kering kecambah normal (1.14 g), dan bobot kering benih (4.30 g), sedangkan nilai vigor benih kontrol ditunjukkan pada parameter indeks vigor (52.33\%) dan kecepatan tumbuh $\left(22.72 \%\right.$ KN.etmal $\left.{ }^{-1}\right)$. Nilai mutu yang dihasilkan perlakuan kontrol menunjukan benih okra pada kedua varietas memiliki mutu fisiologi yang tinggi. Hal serupa ditemukan dalam penelitian Tresniawati et al. (2014), bahwa daya berkecambah $(76.00 \%)$ dan indeks vigor $(49.33 \%)$ tertinggi dihasilkan perlakuan kontrol pada tanaman kemiri sunan. Pada faktor varietas, Naila memiliki bobot 1,000 butir (67.28 g) dan bobot kering benih (4.36 g) lebih besar dibandingkan Zahira, sedangkan varietas Zahira (25.88\%KN.etmal ${ }^{-1}$ ) memiliki kecepatan tumbuh yang lebih cepat dibandingkan Naila (Tabel 5).

Tabel 5. Pengaruh penjarangan buah dan varietas terhadap DB, IV, KCT, BKKN, bobot 1,000 butir, dan BKB pada tanaman okra

\begin{tabular}{lcccccc}
\hline Perlakuan & DB (\%) & IV (\%) & $\mathrm{K}_{\mathrm{CT}}\left(\% \mathrm{KN}\right.$. etmal $\left.^{-1}\right)$ & BKKN $(\mathrm{g})$ & Bobot 1,000 butir $(\mathrm{g})$ & $\mathrm{BKB}(\mathrm{g})$ \\
\hline Penjarangan buah & & & & & & \\
$\quad$ Kontrol & 86.00 & 52.33 & 22.72 & 1.14 & $63.14 \mathrm{c}$ & 4.30 \\
$1.1 \mathrm{P}$ & 88.66 & 45.67 & 24.09 & 1.16 & $67.89 \mathrm{a}$ & 4.27 \\
$1.2 \mathrm{P}$ & 79.66 & 51.67 & 25.04 & 1.18 & $66.39 \mathrm{ab}$ & 4.28 \\
$2.1 \mathrm{P}$ & 75.66 & 38.00 & 22.69 & 0.94 & $67.99 \mathrm{a}$ & 4.34 \\
$2.2 \mathrm{P}$ & 80.33 & 34.33 & 24.79 & 1.12 & $64.58 \mathrm{bc}$ & 4.30 \\
Varietas & & & & & & \\
$\quad$ Naila & 81.46 & 48.67 & $21.85 \mathrm{~b}$ & 1.15 & $67.28 \mathrm{a}$ & $4.36 \mathrm{a}$ \\
Zahira & 82.66 & 40.13 & $25.88 \mathrm{a}$ & 1.06 & $64.72 \mathrm{~b}$ & $4.23 \mathrm{~b}$ \\
\hline
\end{tabular}

Keterangan: $\mathrm{DB}=$ daya berkecambah; $\mathrm{IV}=$ indeks vigor; $\mathrm{BKKN}=$ bobot kering kecambah normal; $\mathrm{K}_{\mathrm{CT}}=$ kecepatan tumbuh; $\mathrm{KN}=$ kecambah normal; BKB = bobot kering benih. Angka yang diikuti huruf yang sama dalam kolom yang sama menunjukkan hasil yang tidak berbeda nyata pada uji DMRT dengan taraf $\alpha=0.05$

\section{KESIMPULAN}

Penjarangan dua buah pertama dengan selang satu menjadi rekomendasi perlakuan untuk mendapatkan parameter unggul pada panjang buah, bobot buah, dan bobot 1,000 butir benih pada tanaman okra. Perlakuan kontrol dijadikan pembanding antara perlakuan penjarangan buah untuk menghasilkan parameter unggul mutu fisiologi benih (daya berkecambah, indeks vigor, kecepatan tumbuh bobot kering kecambah normal), kadar air benih dan bobot kering benih pada okra. Varietas Naila dan Zahira menunjukkan hasil yang berbeda pada paraemeter komponen hasil dan mutu benih. Varietas Naila memiliki mutu fisik (kadar air benih, bobot 1,000 butir dan bobot kering benih) yang lebih unggul dari Zahira, sedangkan varietas Zahira memiliki mutu fisiologi benih (kecepatan tumbuh) yang lebih unggul dari Naila.

\section{UCAPAN TERIMAKASIH}

Terimakasih diucapkan kepada Kementrian Ristekdikti yang telah membiayai penelitian ini melalui Hibah Insinas tahun 2018 atas nama Muhamad Syukur.

\section{DAFTAR PUSTAKA}

Borras, L., G.A. Slafer, M.E. Otegui. 2004. Seed dry weight response to source-sink manipulations in wheat, maize, and soybean: a quantitive reappraisal. Field Crops Res. 86:131-146.

Bortey, H.M., B.M. Dzomeku. 2016. Fruit and seed quality of okra (Abelmoschus esculentus (L.) Moench) as influenced by harvesting stage and drying method. Indian J. Agric.Res. 50:330-334. 
Darmawan, A.C., Respartijati, L. Soetopo. 2014. Pengaruh tingkat kemasakan benih terhadap pertumbuhan dan produksi cabai rawit (Capsicum frustescent (L.)) varietas Comexio. J. Produksi Tanaman 2:339-346.

Delgado, J.A., E. Obis, V. Yuste. 2010. Effect of fruit thinning on fruit and seed features of Cistus ladanifer. Plant Ecol. 211:297-303.

Dubey, P., S. Mishra. 2017. Effect of okra seed in reduction of cholestrol. J. Enthomol. and Zool. Stud. 5:94-97.

Erogul, D., F. Sen. 2015. Effect of giberelic acid treatments on fruit thinning and fruit quality in Japanese plum (Prunus salicina Lindl.). Sci. Hort. 186:137-142.

[ISTA] International Seed Testing Association. 2014. Internasional Rules for Seed Testing. Switzerland, $\mathrm{CH}$.

[Litbangtan] Penelitian dan Badan Pengembangan Pertanian. 2017. Budidaya dan Produksi Benih Okra. http://hortikultura.litbang.pertanian.go.id/ teknologidetail-93.html. [13 Januari 2019].

Menzel, C.M. 2019. Temperature has a greater effect on fruit growth than defoliation or fruit thinning in strawberries in the subtropics. Agriculture 9:127139.
Pathirana, C.K., I.D.C. Sajeevika, P.R.S. Pathirana, H. Fonseka, R.M. Fonseka. 2014. Effect of canopy management and fruit thinning on seed quality of tomato (Solanum lycopersicum L.) variety Thilina. Trop. Agric. Res. 25:171-179.

Sakhidin. 2010. Pengaruh jumlah dan kriteria buah muda yang dipertahankan terhadap hasil buah mangga. J. Pembangunan Pedesaan 10:102-107.

Tabasi, A., H. Nemati, A. Tehranifar, M. Akbari. 2011. The effect of shrubs pruning and fruit thinning on seed germination and seedling of tomato in the next generation (Lycopersicon esculentum Mill.). J. Biol. Environ. 5:105-110.

Tresniawati, C., E. Murniati, E. Widajati. 2014. Perubahan fisik, fisiologi, dan biokimia selama pemasakan benih dan studi rekalsitransi benih Kemiri Sunan. J. Agron. Indonesia 42:74-79.

Yuniarti, N., Megawati, B. Laksono. 2013. Pengaruh metode ekstraksi dan ukuran benih terhadap mutu fisik-fisiologis benih Acacia crassicarpa (A.) Pedley. J. Penel. Hutan Tan. 10:129-137. 